\title{
Food safety: a tall mountain to climb
}

Keywords: safe food, developed, manner, glass, countless, neglect, delivered, found, individuals, manufacturing

\section{Opinion}

In the 1960's when Pillsbury developed a HACCP program in order to provide a safe food supple to NASA's space program, I sure there were obstacles to overcome. But they accomplished and delivered what they set out to do. Food made in the safest manner possible with little to no margin of error. A short time later Pillsbury had a food safety issue of their own when glass was detected in farina which is normally used in cereal for infants. Proof that no single plan is perfect for all types of food manufacturing. As time passed, more HACCP principals were implemented as many other products with unique qualities and issues arose. In 1969 Pillsbury's training program for the FDA titled "Food Safety through the Hazard Analysis and Critical Control Point System" was born. HACCP had made its debut and through the years, the HACCP program has found its way into manufacturing facilities around the world. Much has been learned and yet we still face many obstacles and challenges to overcome. There are countless recalls surfacing and companies have been found guilty of neglect causing countless individuals to contract food borne illness and sadly many have died due to the same neglect. It seems the further science has come, the more numerous the issues have become. That is not even touching on the issue of food fraud and the people which would be needed to combat that. There has been some statistics which have shown that a large number of food borne illness cases have come from the restaurant and food service industry. Are these establishment not smaller versions of food manufacturing facilities? They all buy ingredients, prepare food and sell or serve to their customers. I really can see no difference other than the size of the business. I feel these food service establishments do not face the same scrutiny as the larger facilities which face regular inspections. Some facilities have inspectors on site on a full time basis. Given the scope
Volume 4 Issue 4 - 2017

\author{
Rene Duchesne \\ Food Safety Manager, Cavalier Candies Ltd, Canada
}

Correspondence: Rene Duchesne, Food Safety Manager Cavalier Candies Ltd, Canada, Tel 204-957-8777, Fax 204-9472044,Email rduchesne@cavaliercandies.com

Received: June 29, 2016 | Published: May 10, 2017

which food service covers, it is not unbelievable that many inspectors would be needed to be involved in such a huge undertaking. Area or Provincial Health Inspectors do make it to these establishments, but the shear number of inspections needed and the few inspectors that are given the daunting task of inspecting all of them makes it difficult to visit multiple times per year. This allows many issues to develop and overwhelm owners. Restraints on government funding for food safety is a huge challenge which likely will not be solved in the short term. Yet food safety is a non-stop around the clock, seven day a week opportunity for something to go terribly wrong and innocent people who may fall ill or even worse, die. It seems we've come so far with food safety and still have so much more to do. Is the world's food supply safe for consumers? In my opinion, there is much more safe food produced than unsafe food and therefore my answer is yes.

\section{Acknowledgements}

None.

\section{Conflict of interest}

The author declares no conflict of interest. 